\title{
RESOURCES USED BY THE SUS WITH RESECTION OF NON - PALPABLE BREAST CODES FROM 2015 TO 2017
}

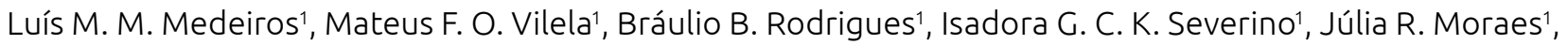
Lara C. R. Alvarenga', Mirian P. Silva'

${ }^{1}$ Centro Universitário de Anápolis (UniEVANGÉLICA) - Anápolis (GO), Brazil.

Objectives: To evaluate the expenditures to the health system with the non-palpable breast node resection procedure in the Unified Health System (SUS) between the years 2015 and 2017. Methodology: This is a retrospective and quantitative study with an approach by cross-sectional study carried out in Brazil between the years 2015 and 2017. The sample population was the Hospital Information System (SIH) of SUS with data obtained from the DATASUS platform, of secondary order. The year of the procedure, the emergency or elective care, the region of the country and the average hospitalization value, the total value per year, the days of hospitalization and the public or private nature were used with variables. Results: Between 2015 and 2017 a total of 17,703,833 million reais were spent on resection of non-palpable breast lesions with oncology marking, and the year 2017 represented the highest percentage of expenditures, with $34 \%$ of total value. The years 2015 and 2016 represented similar but smaller expenditures, with $32.5 \%$ and $33.4 \%$, respectively. In addition to being the year in excess of expenses, 2017 was also the year in which there was a higher hospital admission authorization (AIH), with 4,880, representing 33.8\%, while the other years were $32.5 \%$ in 2015 , and $33.6 \%$ in 2016. According to the AIH, the cost for each hospitalization has an average value of 1878.15 reais per patient who needs the procedure. Among the regions of Brazil, the highest number of AIH approved in the Southeast Region is $44.11 \%$, followed by the Northeast Region, with $30.9 \%$ and the South Region, with $22.11 \%$. The Midwest and North regions totaled $1.6 \%$ and 1.1\%, respectively. Most of the procedures were carried out on an elective basis and little in an emergency, representing $81.8 \%$ for the first option and $18.2 \%$ for the second. Regarding the payment scheme, $73.5 \%$ of the procedures are in the category ignored, while a small amount, $3.4 \%$, were in the private regime and $23 \%$ in the public regime. Conclusion: It is noticed that breast cancer is still a neoplasia present in the population due to the large number of procedures that are performed for the reversal and improvement of the patient's condition. Still, it is a pathology that demands large expenditures to the Brazilian public and private health system, with coverage in all regions of the country, however, with emphasis on the Southeast Region, where there was a greater quantity of AIH approved, while the North Region exhibited the less quantity. 